\title{
New Insights into Benzene Hydrocarbon Decomposition from Fuel Exhaust Using Self-Support Ray Polarization Plasma with $\mathrm{Nano}^{-\mathrm{TiO}_{2}}$
}

\author{
Tao Zhu, ${ }^{1}$ Wenjuan Zhao, ${ }^{1}$ Wenjing Zhang, ${ }^{2} \mathrm{Ni}$ Xia, ${ }^{1}$ and Xiaoyang $\mathrm{Li}^{1}$ \\ ${ }^{1}$ School of Chemical \& Environmental Engineering, China University of Mining \& Technology-Beijing, Ding 11, \\ Xueyuan Road, Haidian District, Beijing 100083, China \\ ${ }^{2}$ Chinese Academy for Environmental Planning, No. 8, Dayangfang Road, Chaoyang District, Beijing 100012, China \\ Correspondence should be addressed to Tao Zhu; bamboozt@cumtb.edu.cn
}

Received 17 June 2015; Revised 11 August 2015; Accepted 3 September 2015

Academic Editor: Hao Tang

Copyright (C) 2015 Tao Zhu et al. This is an open access article distributed under the Creative Commons Attribution License, which permits unrestricted use, distribution, and reproduction in any medium, provided the original work is properly cited.

\begin{abstract}
A new insight into self-support ray polarization (SSRP) of nonthermal plasma for benzene hydrocarbon decomposition in fuel exhaust was put forward. A wire-tube dielectric barrier discharge (DBD) AC plasma reactor was used at atmospheric pressure and room temperature. The catalyst was made of nano- $\mathrm{TiO}_{2}$ and ceramic raschig rings. Nano- $\mathrm{TiO}_{2}$ was prepared as an active component by ourselves in the laboratory. Ceramic raschig rings were selected for catalyst support materials. Then, the catalyst was packed into nonthermal plasma (NTP) reactor. Six aspects, benzene initial concentration, gas flux, electric field strength, removal efficiency, ozone output, and $\mathrm{CO}_{2}$ selectivity on benzene removal efficiency, were investigated. The results showed SSRP can effectively enhance benzene removal efficiency. The removal efficiency of benzene was up to $99 \%$ at electric field strength of $12 \mathrm{kV} / \mathrm{cm}$. At the same time, SSRP decreases ozone yield and shows a better selectivity of $\mathrm{CO}_{2}$ than the single technology of nonthermal plasma. The final products were mostly $\mathrm{CO}, \mathrm{CO}_{2}$, and $\mathrm{H}_{2} \mathrm{O}$. Our research will lay the foundation for SSRP industrial application in the future.
\end{abstract}

\section{Introduction}

Since 1997, after the use of unleaded gasoline, gasoline composition and chemical composition of automobile emissions in Beijing have changed. Now, automobile exhaust pollutants mainly consist of the mixtures of fuel evaporation and incomplete combustion products. Lu et al. [1] established the source component spectrum of automobile exhaust and the spectrum of gasoline vapor and liquid gasoline volatile organic compounds (VOCs), including gasoline, diesel, and liquefied petroleum gas (LPG) as the fuel by sampling on site and the data normalization processing method. It was found that benzene, toluene, xylene, 1,2,4-trimethyl benzene, and other aromatic compounds have higher proportion in gasoline and diesel exhaust. Some researchers have found that some membranes like CNT membranes could be used to filtrate benzene hydrocarbon [2]. Aromatic volatile organic compounds, due to their toxicity and harm on the atmospheric environment, attract widespread concern of scholars at home and abroad [3-6].

In recent years, nanometer photocatalysis processes for VOCs decomposition have received considerable attention because of low energy consumption, high efficiency, and no secondary pollution. Photochemical reactor is the core equipment of photocatalysis process, and solid phase photocatalytic oxidation reactor and fixed bed reactor are mainly used at present. However, these reactors cannot deal well with VOCs from automobile emission so far. Therefore, how to improve ideal photocatalysis reactor has become the key for VOCs decomposition.

The author uses self-support ray polarization (SSRP) of nonthermal plasma (NTP) for benzene hydrocarbon removal in fuel exhaust. A wire-tube dielectric barrier discharge (DBD) AC plasma reactor was used at atmospheric pressure and room temperature. The catalyst was made of nano- $\mathrm{TiO}_{2}$ and ceramic raschig rings. Nano- $\mathrm{TiO}_{2}$ was prepared as an 


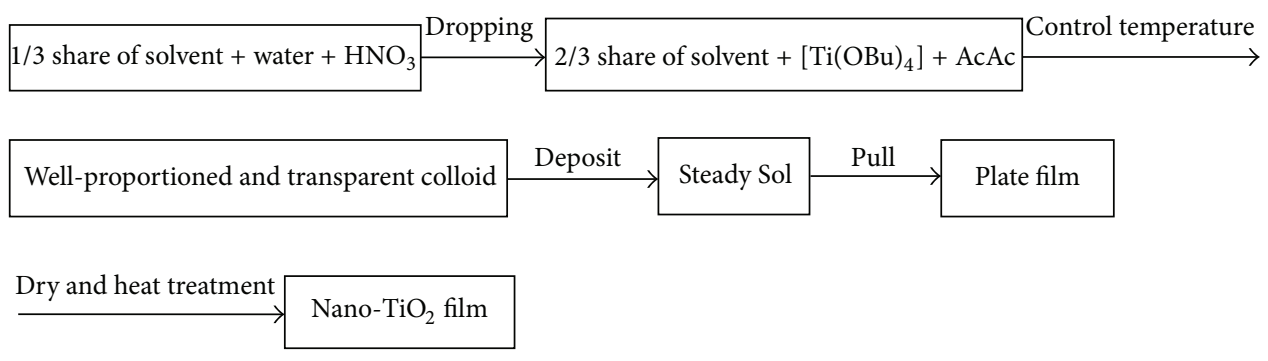

FIGURE 1: Flow chart on preparing nano- $\mathrm{TiO}_{2}$ thin film by Sol-Gel method.

active component by us in the laboratory. Ceramic raschig rings were selected for catalyst support materials. Then, the catalyst was packed into nonthermal plasma (NTP) reactor [7].

When imposing external voltage on plasma reactor's discharge electrode, a mess of micro discharges will be generated along with gas discharge. These micro discharges come with a certain amount of ultraviolet. Once the photocatalyst was packed into NTP reactor, these ultraviolet lights would activate the photocatalysts with gas discharge happening to treat gaseous VOCs. Ceramic raschig rings, as the main carrier of nano- $\mathrm{TiO}_{2}$ photocatalyst, lead to chemical reactions in the photocatalyst surface. SSRP generated with plasma happens to promote the photocatalytic reaction. Plasma and photocatalyst work together to improve the removal efficiency of the gaseous pollutants. So SSRP has a better degradation effect than general fixed bed reactor.

\section{Materials and Methods}

2.1. Materials Preparation. Nano-TiO 2 films were prepared by the Sol-Gel method in the experiment [8]. Flow chart on preparing nano- $\mathrm{TiO}_{2}$ thin film by Sol-Gel method is given in Figure 1.

Precursor solution is as follows: 1 mol tetrabutyl titanate (precursor substance) $+12 \mathrm{~mol}$ ethanol (solvent) $+1.2 \mathrm{~mol}$ acetylacetone (chelating reagent).

Droplet solution is as follows: $6 \mathrm{~mol}$ ethanol (solvent) + 1 mol $\mathrm{HNO}_{3}$ (catalyzer) $+2.5 \mathrm{~mol}$ distilled water.

Droplet solution was dropped slowly into the original solution at $35^{\circ} \mathrm{C}$ and the whole solution was mixed well together. The steady Sol would be obtained, and then the Sol should be deposited at least 24 hours. The packed materials (i.d. $5 \mathrm{~mm}$, thickness $3 \mathrm{~mm}$, length $10 \mathrm{~mm}$, raschig ceramic ring) must be washed by microwave cleaning apparatus before they were immersed into the Sol. Later, the packed materials were pulled out from the Sol at the speed of $1.5 \mathrm{~mm} / \mathrm{s}$ to get the nanometer $\mathrm{TiO}_{2}$ film. The packed materials with nanometer film would be dried at $80^{\circ} \mathrm{C}$ for one hour before they were put into a muffle furnace to calcine at $450 \sim$ $600^{\circ} \mathrm{C}$ for two hours. At last, the film gradually refrigerated to ambient temperature [9].

In this experiment, we platted nano- $\mathrm{TiO}_{2}$ thin film on the surface of ceramic raschig rings 3 times, and the weight of nano- $\mathrm{TiO}_{2}$ thin film was $0.003 \mathrm{~g} / \mathrm{cm}^{2}$. Ceramic raschig ring was selected with length of $1 \mathrm{~cm}$ and wall thickness of $1 \mathrm{~mm}$ and inner diameter of $5 \mathrm{~mm}$ as catalyst carrier. The structure of ceramic raschig ring is tested by X-Ray Diffraction (XRD) and can be seen in Table 1 .

2.2. NTP System. The NTP system consisted of a tubewire packed-bed reactor system, an AC power supply, a continuous flow gas supplying system, and an electric and gaseous analytical system. The schematic diagram of NTP system is shown in Figure 2. Dry air $\left(78 \% \mathrm{~N}_{2}, 21 \% \mathrm{O}_{2}\right)$ was used as a balance gas for benzene decomposition. Air supplied from an air compressor was divided into two air flows with each flow rate controlled by a mass flow controller (MFC). One dry air flow was introduced into a bottle of liquid benzene to produce saturated benzene. The vapor was then mixed with the other dry air flow in a blender so that benzene waste gas was diluted to a desired concentration. The voltage and current waves were measured by oscilloscope (Tektronix 2014). The voltage applied to the reactor was sampled by a $12500: 1$ voltage divider. Also, the current was determined from the voltage drop across a shunt resistor $(R 3=10 \mathrm{k} \Omega)$ connected in series with the grounded electrode. In order to obtain the total charge and discharge power, simultaneously, a capacitor $\left(C_{m}=2 \mu \mathrm{F}\right)$ was placed instead of the shunt resistor. The electrical power provided to the discharge was measured using the $Q-V$ Lissajous diagram. The power source used in the experiment is high voltage alternate current power supply whose frequency is $50 \mathrm{~Hz}$, ranging from 0 to $30 \mathrm{kV}$.

The NTP packed-bed reactor was shown in Figure 3. The coaxial cylindrical NTP reactor was made of an organic-glass tube with an inner diameter of $50 \mathrm{~mm}$ and wall thickness of $5 \mathrm{~mm}$ wrapped by a copper mesh of $50 \mathrm{~cm}$ in length as a ground electrode. A tungsten wire $(1.5 \mathrm{~mm}$ in diameters) placed on the axis of NTP reactor served as the inner discharge electrode. The relative humidity of $25 \%$ in NTP reactor was controlled by a thermohygrometer.

2.3. Detect Methods. Adapt the production to benzene gas concentration detected by Gas Chromatography-Mass Spectrometer (produced by American Thermos Finnegan, TRACE-MS) matching hydrogen flame ion detector (FID); minimum detection quantity can reach 10-15 g. Chromatographic column is $30 \mathrm{~m}$ long, with inner diameter $0.32 \mathrm{~mm}$ and DB-1 nonpolar capillary column. Choose iodine quantity method to determine ozone concentration. Use Tektronix TDS2014 type oscilloscope to measure discharge parameters in experiment process. Use Lissajous method to determine 
TABLE 1: Physics characteristics of the packed material raschig ceramic ring.

\begin{tabular}{lcccccc}
\hline & \multicolumn{2}{l}{ Component/\% } & Interstitial rate \% & Hygroscopic coefficient \% & Volume density $\left(\mathrm{g} \cdot \mathrm{cm}^{-3}\right)$ & Hole rate $\%$ \\
Quartz & $\mathrm{Al}_{2} \mathrm{O}_{3}$ & Noncrystal & & 5.9 & 2.17 & 12.7 \\
\hline 15 & 35 & 50 & 9.4 & & 5.9 \\
\hline
\end{tabular}

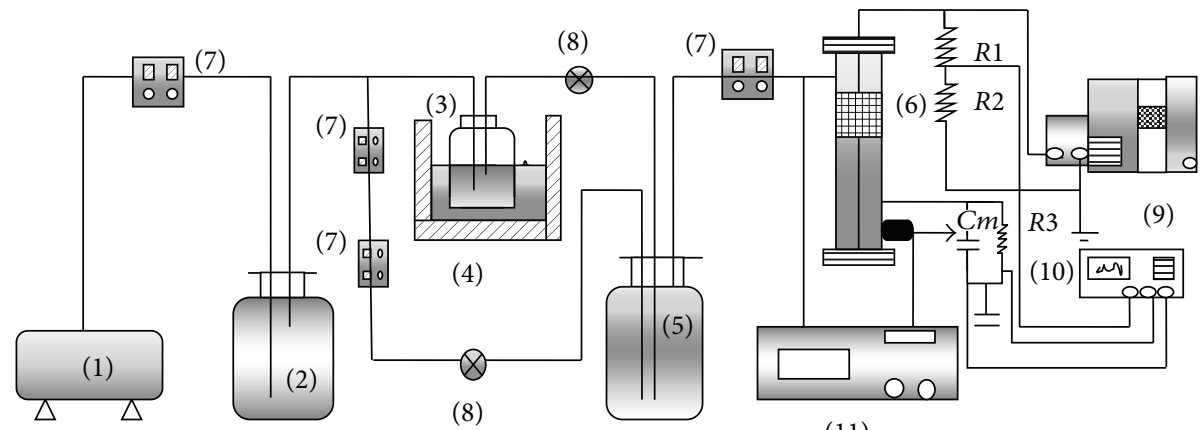

(11)
(1) Air compressor
(7) Mass flow meter
(2) Buffer
(8) Needle valve
(3) Benzene liquid bottle
(9) High voltage
(4) Attemperator
(10) Oscillograph
(5) Blender
(11) Gas chromatograph
(6) NTP reactor

FIGURE 2: Schematic diagram of NTP system for benzene removal.

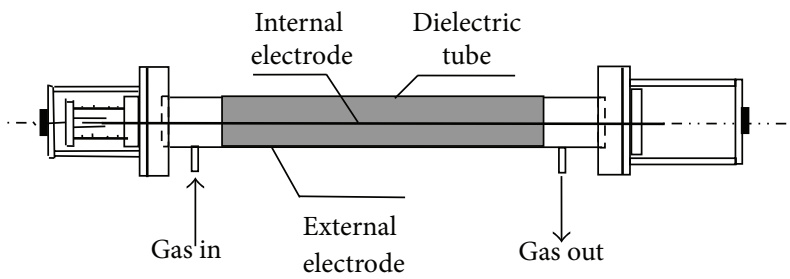

FIGURE 3: NTP reactor. Reactor: organic-glass tube (i.d. $32 \mathrm{~mm}$, packed infilling length of packed materials of $200 \mathrm{~mm}$ ); internal electrode: tungsten filament (i.d. $0.5 \mathrm{~mm}$ ); external electrode: dense steel mesh.

discharge power. Use the domestic SC-1001 type Gas Chromatograph to detect $\mathrm{CO}_{2}$ and $\mathrm{CO}$ content in final product, matching hydrogen flame ion detector (FID); methanation converter is connected to the detection top, the minimum detection quantity is $10-12 \mathrm{~g}$, and linear range is $10^{7}$. The surface characteristic of $\mathrm{TiO}_{2}$ samples was detected by XRD.

Evaluation standard of benzene degradation effect is evaluated by the following calculation equations:

$$
\begin{aligned}
\eta & =\frac{C_{0}-C}{C_{0}} \times 100 \% \\
s_{\mathrm{CO}_{2}} & =\frac{C_{\mathrm{CO}_{2}}}{n \times\left(C_{0}-C\right)} \times 100 \% .
\end{aligned}
$$

In (1), $\eta$ represents removal efficiency of the benzene, \%; $\mathrm{C}_{0}$ represents benzene gas inlet mass concentration, $\mathrm{mg} / \mathrm{m}^{3}$; $C$ is the mass concentration of outlet benzene, $\mathrm{mg} / \mathrm{m}^{3}$. In (2),

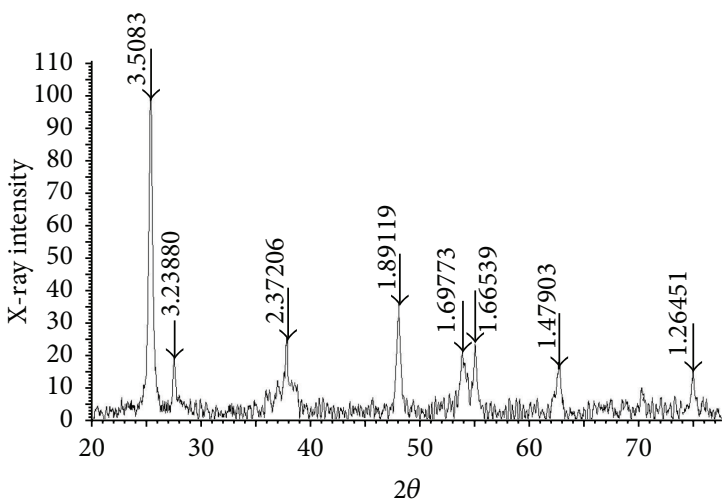

FIGURE 4: XRD of nano-titania.

$s_{\mathrm{CO}_{2}}$ represents the selectivity of $\mathrm{CO}_{2}$ after benzene degradation reaction, \%; $C_{\mathrm{CO}_{2}}$ represents the quality concentration after reaction, $\mathrm{mg} / \mathrm{m}^{3}$; and $n$ represents the carbon atom number VOCs molecule contains.

\section{Results and Discussion}

3.1. Characterization of $\mathrm{Nano}-\mathrm{TiO}_{2}$. To carry out XRD phase analysis for prepared $\mathrm{TiO}_{2}$ samples, XRD spectra are shown in Figure 4. There are two kinds of crystal of rutile and anatase in the phase because of heat treatment temperature of $600^{\circ} \mathrm{C}$ for $\mathrm{TiO}_{2}$ photocatalyst preparation. The mass ratio of anatase crystal and rutile crystal is $17: 3$, and anatase crystal is the main component of $\mathrm{TiO}_{2}$ catalysts [10]. At the same time, 

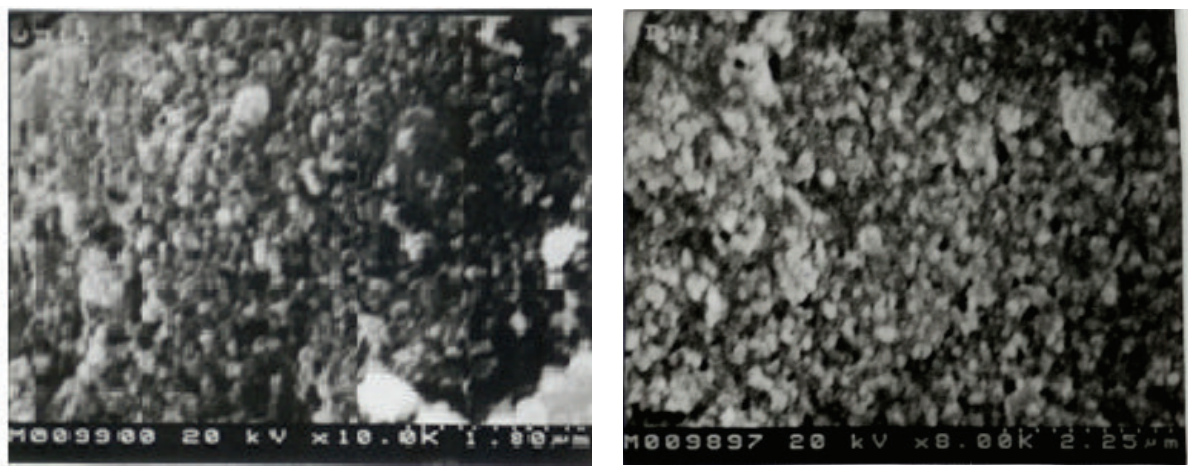

Figure 5: SEM micrograph of $\mathrm{TiO}_{2}$.

XRD detected results show that the average particle size of anatase crystals of $\mathrm{TiO}_{2}$ is $28.7 \mathrm{~nm}$, and the average particle size of rutile crystal of $\mathrm{TiO}_{2}$ is $35.1 \mathrm{~nm}$.

The nanometer $\mathrm{TiO}_{2}$ thin film was inspected and analyzed by Scan Electric Mirror (SEM, made in Japan, S2700). The results of SEM micrograph showed that average particulate diameters of $\mathrm{TiO}_{2}$ were less than $100 \mathrm{~nm}$. SEM micrograph of the samples is referred to in Figure 5.

\subsection{Effect of Self-Support Photocatalytic on Removal Efficiency} of Benzene. Figure 7 shows the relationship between electric field strength and removal efficiency with or without catalysts. Benzene removal efficiency is increased to over $80 \%$, and removal efficiency increases $10 \%$ with catalyst compared to that without catalyst in the conditions of benzene concentration $\left(C_{0}\right)$ of $600 \mathrm{mg} / \mathrm{m}^{3}$ and electric field strength $(E)$ of $9 \mathrm{kV} / \mathrm{cm}$. Benzene is triggered not only to form $\mathrm{C}_{6} \mathrm{H}_{5}{ }^{\bullet}$ but to form short carbon chain radicals and molecular fragments. Medium stops free radicals, such as ${ }^{\circ} \mathrm{OH}$, ${ }^{\circ} \mathrm{O}$ from oxidizing $\mathrm{C}_{6} \mathrm{H}_{5}{ }^{\circ}$, molecular fragment, short carbon chain, and CO. Some of the free radicals generated from reactants in the strong electric field happen to be composited again after the reaction zone, so that oxidation of benzene is incomplete. If catalyst was added in the reaction zone, these free radicals as well as oxygen free radical are absorbed on the surface of the catalyst before compositing inactivation. Oxidation reaction occurs further, and the removal efficiency is higher with catalyst than the single DBD. At lower electric field strength, corona discharge is weak within reactor, and corona discharge district concentrates only near corona feeder. At this time, ultraviolet rays discharged are weaker, and the function of $\mathrm{TiO}_{2}$ photocatalyst is weaker. The active free radicals produced by discharging are limited to the surroundings of corona district and cannot react collaboratively with the catalyst of packing surface beyond the corona district. So benzene removal efficiency is approximate with or without catalyst. When electric field strength is gradually enhanced and corona district expands, ultraviolet rays discharged are enhanced and catalytic activity gradually increases. It is obvious that benzene removal efficiency increases. When the electric field strength rises up to a certain degree, catalyst is fully activated, and removal efficiency of benzene tends to be stable.

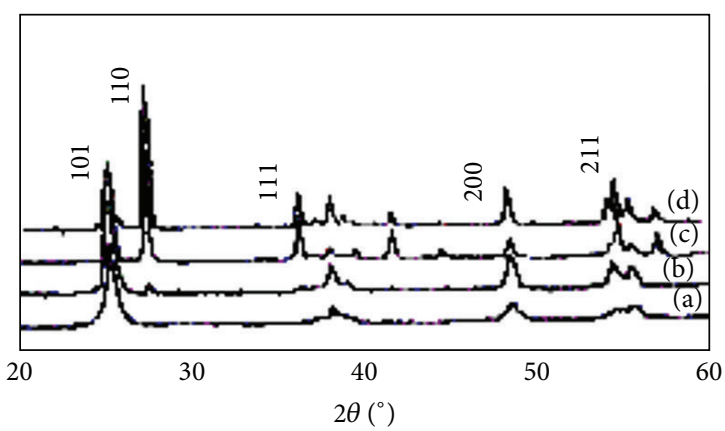
(a) 450
(c) 700
(b) 600
(d) 800

FIgURE 6: The result of $\mathrm{TiO}_{2}$ thin film by heat treatment.

3.3. Effect of Self-Support Photocatalytic on Ozone Generation. Figure 8 shows ozone concentration $\left(\mathrm{C}_{\mathrm{O}_{3}}\right)$ gradually increased with the gas flux $\left(v_{\text {Gas }}\right)$ increasing. $\mathrm{O}_{2}$ concentration increases in the air with gas flux increasing. Under high voltage, energetic electrons are throughout the reactor space, and they bombard $\mathrm{O}_{2}$ molecule to react as follows:

$$
\begin{array}{r}
\mathrm{O}_{2}+\mathrm{e} \longrightarrow{ }^{\bullet} \mathrm{O}+\mathrm{O}^{-} \\
\mathrm{O}+\mathrm{O}_{2}+\mathrm{M} \longrightarrow \mathrm{O}_{3}+\mathrm{M}
\end{array}
$$

Thus, the ozone concentration is in the upward trend.

It can be also seen from Figure 6 that ozone concentration is lower with catalyst than that without catalysts when benzene gas flux entering the reactor is kept the same. It indicates that $\mathrm{TiO}_{2}$ photocatalyst has an inhibitory effect on ozone formation. During the removal of benzene, electronhole pairs are energetic which are from SSRP on the surface of the catalyst. High energy electrons generated in the gases discharge process are preemptively composited with the photo-induced hole to reduce the amount of high energy electron which is used to produce ozone in the air. So ozone yield decreases.

Figure 9 shows the relationship between benzene initial concentration $\left(C_{0}\right)$ and ozone concentration $\left(C_{\mathrm{O}_{3}}\right)$ with or without catalyst. It can be seen from Figure 8 that ozone concentration increases with benzene initial concentration 


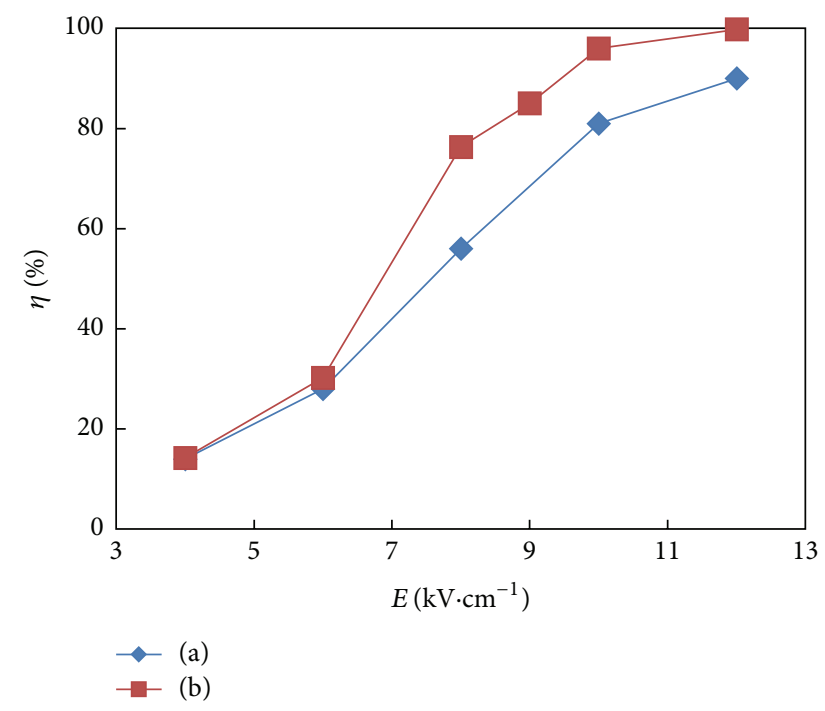

FIgURE 7: Relationship between electric field strength $(E)$ and removal efficiency $(\eta)$ with or without catalyst $\left(v_{\mathrm{Gas}}=100 \mathrm{~L} / \mathrm{h} ; C_{0}\right.$ $=600 \mathrm{mg} / \mathrm{m}^{3}$ ): (a) without catalyst, (b) with catalyst.

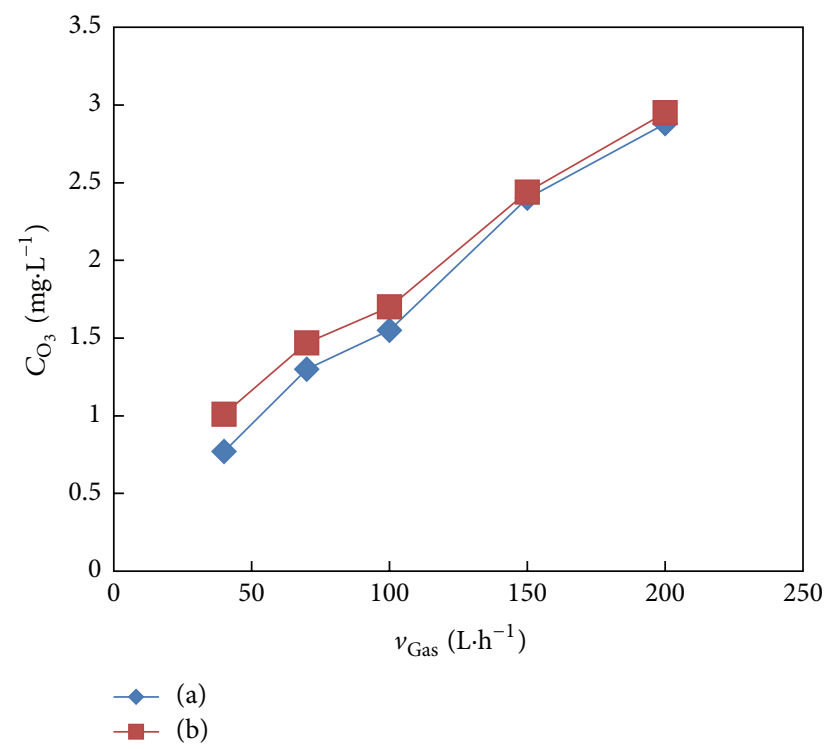

FIGURE 8: Relationship between gas flux ( $v_{\text {Gas }}$ ) and ozone concentration $\left(C_{\mathrm{O}_{3}}\right)$ with or without catalyst $\left(C_{0}=600 \mathrm{mg} / \mathrm{m}^{3} ; E=12 \mathrm{kV} / \mathrm{cm}\right)$ : (a) without catalyst, (b) with catalyst.

decreasing. When $\mathrm{C}_{0}$ rises, $\mathrm{C}_{6} \mathrm{H}_{6}$ molecules cost part of the free electrons and free radicals to affect ozone generation. We found that $\mathrm{C}_{6} \mathrm{H}_{6}$ still exists in emission gas in the case of high $\mathrm{O}_{3}$ concentrations through Gas ChromatographyMass Spectrometry (GC-MS). It indicates that $\mathrm{O}_{3}$ does not react with $\mathrm{C}_{6} \mathrm{H}_{6}$ directly. That means ozone decomposes into radical fragments firstly, rather than reacting directly with benzene, and free radicals, such as ${ }^{\circ} \mathrm{OH}$, ${ }^{\circ}$, play a major role as oxidants. This conclusion is supported previously by Assadi et al. [11].

3.4. Effect of Self-Support Photocatalytic on $\mathrm{CO}_{2}$ and $\mathrm{CO}$ Concentration and $\mathrm{CO}_{2}$ Selectivity. Figure 10 shows the relationship between electric field strength $(E)$ and $\mathrm{CO}_{2}$ and $\mathrm{CO}$ concentration $\left(C_{\mathrm{CO}_{2}}, C_{\mathrm{CO}}\right)$ with or without catalyst. $C_{\mathrm{CO}_{2}}$ and $C_{\mathrm{CO}}$ increase with the electric field strength increasing. When the electric field strength is $12 \mathrm{kV} / \mathrm{cm}, C_{\mathrm{CO}_{2}}$ is 3.5 times higher than $C_{\mathrm{CO}}$. As the field strength increases, energetic electron, $\mathrm{O}_{3}$, and other oxidizing radicals increase in the NTP process. At the same time, there are a large amount of electron-hole pairs and ${ }^{\circ} \mathrm{OH},{ }^{\circ} \mathrm{O}$ radicals in SSRP process. They work together with benzene molecules to decompose to $\mathrm{CO}_{2}$ and $\mathrm{CO}$. It was found that when the electric field intensity is higher than $12 \mathrm{kV} / \mathrm{cm}$, except of $\mathrm{CO}, \mathrm{CO}_{2}$, and $\mathrm{H}_{2} \mathrm{O}$, no other products were found in the emission exhaust through GC-MS.

Figure 11 shows the relationship between electric field strength $(E)$ and $\mathrm{CO}_{2}$ selectivity $\left(s_{\mathrm{CO}_{2}}\right)$ with or without photocatalyst. $s_{\mathrm{CO}_{2}}$ increases with the electric field strength increasing. When the electric field strength is $11 \mathrm{kV} / \mathrm{cm}, s_{\mathrm{CO}_{2}}$ is $15 \%$ higher with catalyst than that without catalyst. It means SSRP is favorable to improving $s_{\mathrm{CO}_{2}}$. SSRP not only improves the reaction selectivity of benzene molecules in the plasma region and on the surface of the catalyst but also makes byproducts generated in NTP process oxidize into $\mathrm{CO}, \mathrm{CO}_{2}$ in NTP region and on the surface of catalyst finally.

\section{Reaction Mechanism}

Ultraviolet rays coming from plasma's self-support ray polarization provide a good power source for nanometer photocatalytic materials. When the UV radiates nano- $\mathrm{TiO}_{2}$ photocatalyst, the catalyst's surface will produce electron and hole which react with $\mathrm{O}_{2}$ or $\mathrm{H}_{2} \mathrm{O}$ adsorbed on the surface, generating $\mathrm{OH}$ free radical, as a result, and react with $\mathrm{VOC}_{\mathrm{S}}$ [12]. Plasma self-support ray polarization reactor adheres to the following 3 procedures in treatment of $\mathrm{VOC}_{S}$ :

(1) Energetic electron bombards $\mathrm{VOC}_{\mathrm{S}}$ to inspire, ionize, and dissociate chemical bond breaking, thus playing the role of damaging $\mathrm{VOC}_{\mathrm{s}}$.

(2) There exist large amounts of free radicals and ozone in the plasma, which oxidize $\mathrm{VOC}_{\mathrm{S}}$ to generate $\mathrm{CO}_{2}$, $\mathrm{H}_{2} \mathrm{O}$, and $\mathrm{CO}$.

(3) When the UV radiates nano- $\mathrm{TiO}_{2}$ photocatalyst, the catalyst's surface will produce electron and hole which react with $\mathrm{O}_{2}$ or $\mathrm{H}_{2} \mathrm{O}$ adsorbed on the surface, generating ${ }^{\circ} \mathrm{OH}$ free radical, as a result, and degraded $\mathrm{VOC}_{S}$. Chemical reactions are as follows [13].

The wavelength threshold of the light absorbed is $387.5 \mathrm{~nm}$ corresponding to $\mathrm{TiO}_{2}$ band gap of $3.2 \mathrm{eV}$. When irradiated by the light whose wavelength is less than or equal to $387.5 \mathrm{~nm}$, electron is fired on the valence band to cross the gap band and enter the conduction band [14]. At the same time, the corresponding hole on the valence band produces [15]

$$
\mathrm{TiO}_{2}+\text { plasma } \longrightarrow \mathrm{h}^{+}+\mathrm{e}^{-}
$$

Electron-hole pairs have limited life, and they will soon compound the following reaction:

$$
\mathrm{h}^{+}+\mathrm{e}^{-} \longrightarrow \text { heat }
$$




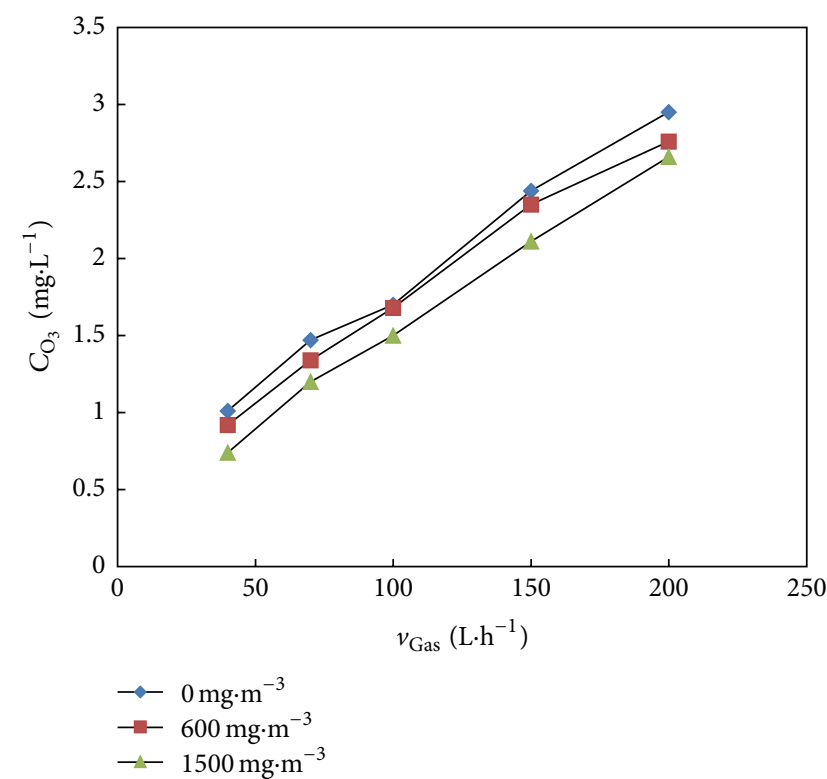

(a) Without catalyst

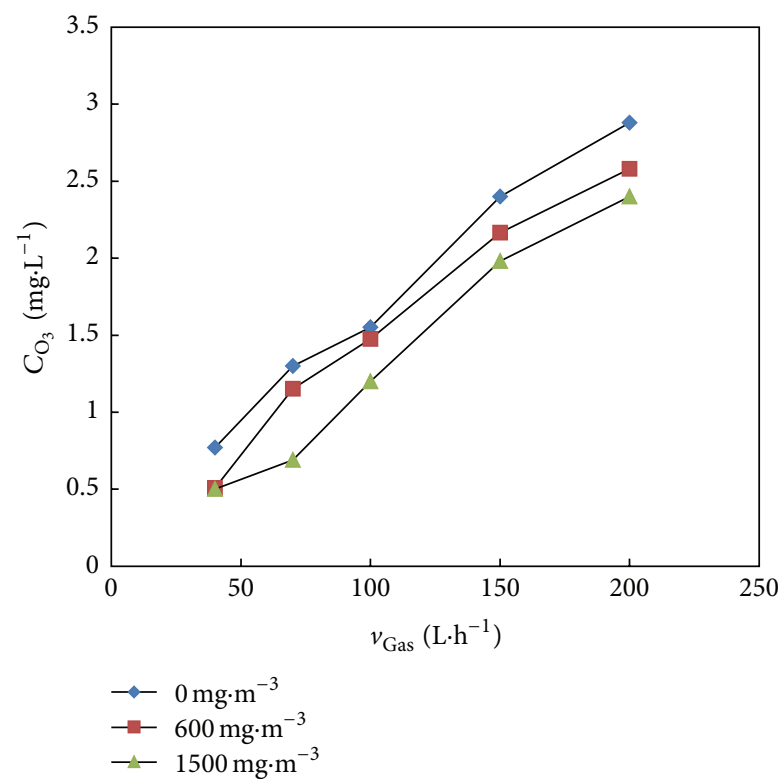

(b) With catalyst

FIGURE 9: Relationship between benzene initial concentration $\left(C_{0}\right)$ and ozone concentration $\left(C_{\mathrm{O}_{3}}\right)$ with or without catalyst $(E=12 \mathrm{kV} / \mathrm{cm})$.

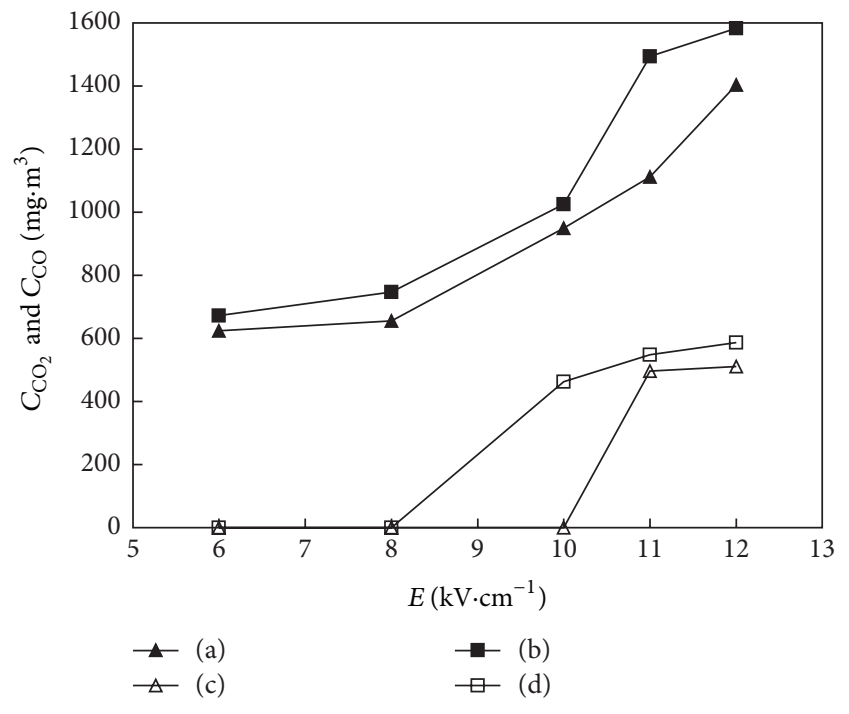

Figure 10: Relationship between electric field strength $(E)$ and $\mathrm{CO}_{2}$ and $\mathrm{CO}$ concentration with or without catalyst $\left(C_{0}=600 \mathrm{mg} / \mathrm{m}^{3}\right.$, $E=12 \mathrm{kV} / \mathrm{cm}$, and $\left.v_{\mathrm{Gas}}=100 \mathrm{~L} / \mathrm{h}\right)$. (a) $\mathrm{CO}_{2}$ concentration without catalyst, (b) $\mathrm{CO}_{2}$ concentration with catalyst, (c) $\mathrm{CO}$ concentration without catalyst, and (d) $\mathrm{CO}$ concentration with catalyst.

Photo-induced hole can be captured by the water or hydroxyl absorbed on the surface of catalyst and then produce ${ }^{\circ} \mathrm{OH}$ free radicals:

$$
\begin{aligned}
& \mathrm{h}^{+}+\mathrm{H}_{2} \mathrm{O} \longrightarrow{ }^{\cdot} \mathrm{OH}+\mathrm{H}^{+} \\
& \mathrm{h}^{+}+\mathrm{OH}^{-} \longrightarrow{ }^{\cdot} \mathrm{OH}
\end{aligned}
$$



FIGURE 11: Relationship between electric field strength $(E)$ and $\mathrm{CO}_{2}$ selectivity $\left(s_{\mathrm{CO}_{2}}\right)$ with or without photocatalyst $\left(C_{0}=600 \mathrm{mg} / \mathrm{m}^{3}, E\right.$ $=12 \mathrm{kV} / \mathrm{cm}$, and $\left.v_{\mathrm{Gas}}=100 \mathrm{~L} / \mathrm{h}\right)$.

Photo-induced electron is mainly captured by oxygen adsorbed on the surface of catalyst:

$$
\begin{array}{r}
\mathrm{O}_{2 \mathrm{ads}} \longrightarrow 2 \mathrm{O}_{\mathrm{ads}} \\
\mathrm{O}_{2 \mathrm{ads}}+\mathrm{e}^{-} \longrightarrow \mathrm{O}_{2 \mathrm{ads}}{ }^{-} \\
\mathrm{O}_{\mathrm{ads}}+\mathrm{e}^{-} \longrightarrow \mathrm{O}_{\mathrm{ads}}{ }^{-}
\end{array}
$$


Part of photo-induced hole can be captured by oxygen adsorbed on the surface of catalyst at the same time:

$$
\begin{gathered}
\mathrm{O}_{\mathrm{ads}}{ }^{-}+\mathrm{h}^{+} \longrightarrow \mathrm{O}_{\mathrm{ads}} \\
\mathrm{e}^{-}+\mathrm{H}_{2} \mathrm{O}_{2} \longrightarrow 2 \mathrm{OH}^{\circ} \\
\mathrm{O}_{2}{ }^{-}+\mathrm{H}^{+} \longrightarrow \mathrm{HO}_{2}{ }^{\circ}
\end{gathered}
$$

$\mathrm{OH}^{\bullet}, \mathrm{HO}_{2}{ }^{\circ}, \mathrm{h}^{+}$, plasma, and so forth, as the strongest oxidizing oxidants, join some other free radicals to affect VOCs:

$$
\begin{aligned}
& \mathrm{OH}^{\bullet}, \mathrm{HO}_{2}{ }^{\bullet}, \mathrm{h}^{+} \text {, plasma, etc., }+ \text { VOCs } \longrightarrow \cdots \\
& \longrightarrow \mathrm{CO}_{2}+\mathrm{H}_{2} \mathrm{O}
\end{aligned}
$$

\section{Conclusions}

The authors use SSRP of NTP for benzene hydrocarbon removal in fuel exhaust. A wire-tube dielectric barrier discharge (DBD) AC plasma reactor was used at atmospheric pressure and room temperature. The catalyst was made of nano- $\mathrm{TiO}_{2}$ and ceramic raschig rings. Nano- $\mathrm{TiO}_{2}$ was prepared as an active component by ourselves in the laboratory. Ceramic raschig rings were selected for catalyst support materials. Based on a series of experiments, we draw the following conclusions:

(1) SSRP increases with external electric field strength increasing. When electric field strength is $12 \mathrm{kV} / \mathrm{cm}$, benzene removal efficiency is up to $99 \%$.

(2) Ozone is a typical byproduct in the NTP process. SSRP shows inhibitory effects on the generation of ozone.

(3) $C_{\mathrm{CO}_{2}}, C_{\mathrm{CO}}$, and $s_{\mathrm{CO}_{2}}$ increase with the electric field strength increasing in the products. SSRP shows a good characteristic to improve $s_{\mathrm{CO}_{2}}$ and to promote benzene removal efficiency.

\section{Conflict of Interests}

The authors declare that there is no conflict of interests regarding the publication of this paper.

\section{Authors' Contribution}

T. Zhu and W. J. Zhang contributed to this work as corresponding authors and they conceived and designed the experiments; W. J. Zhao, X. Ni, and X. Y. Li performed the experiments; T. Zhu and W. J. Zhao analyzed the data; W. J. Zhang contributed reagents/materials/analysis tools; and W. J. Zhao wrote the paper.

\section{Acknowledgments}

This work was supported by Special Research Funds for Environmental Protection Public Welfare (no. 201409004), the National Natural Science Foundation of China (no.
51108453), Program for New Century Excellent Talents in University (no. NCET120967), Beijing Outstanding Talent Training Project (no. 2012ZG81), and the Fundamental Research Funds for the Central Universities (no. 2009QH03). Thanks are due to Dr. Annie Zeng in West Virginia University for providing language help and for proofreading the paper.

\section{References}

[1] S. H. Lu, Y. H. Bai, and G. S. Zhang, "Study on characteristics of VOCs source profiles of vehicle exhaust and gasoline emission," Acta Scientiarum Naturalism Universities Pekinensis, vol. 39, pp. 507-511, 2003.

[2] A. Saha, C. M. Jiang, and A. A. Martí, "Carbon nanotube networks on different platforms," Carbon, vol. 79, no. 1, pp. 118, 2014.

[3] A. M. Vandenbroucke, M. Mora, C. Jiménez-Sanchidrián et al., "TCE abatement with a plasma-catalytic combined system using $\mathrm{MnO}_{2}$ as catalyst," Applied Catalysis B: Environmental, vol. 156-157, pp. 94-100, 2014.

[4] T. Zhu, R. Chen, N. Xia et al., "Volatile organic compounds emission control in industrial pollution source using plasma technology coupled with $\mathrm{F}-\mathrm{TiO}_{2} / \gamma-\mathrm{Al}_{2} \mathrm{O}_{3}$," Environmental Technology, vol. 36, pp. 1405-1413, 2015.

[5] F. Rahmani, M. Haghighi, and P. Estifaee, "Synthesis and characterization of $\mathrm{Pt} / \mathrm{Al}_{2} \mathrm{O}_{3}-\mathrm{CeO}_{2}$ nanocatalyst used for toluene abatement from waste gas streams at low temperature: conventional vs. plasma-ultrasound hybrid synthesis methods," Microporous and Mesoporous Materials, vol. 185, pp. 213-223, 2014.

[6] T. Zhu, J. Li, W. Liang, and Y. Jin, "Synergistic effect of catalyst for oxidation removal of toluene," Journal of Hazardous Materials, vol. 165, no. 1-3, pp. 1258-1260, 2009.

[7] T. Zhu, D. Y. Xu, X. W. He et al., "Decomposition of benzene in dry air by super-imposed barrier discharge nonthermal plasmaphotocatalytic system," Fresenius Environmental Bulletin, vol. 19, no. 7, pp. 1275-1282, 2010.

[8] H. B. Zhang, K. Li, T. H. Sun, J. Jia, Z. Lou, and L. Feng, "Removal of styrene using dielectric barrier discharge plasmas combined with sol-gel prepared $\mathrm{TiO}_{2}$ coated $\gamma$ - $\mathrm{Al}_{2} \mathrm{O}_{3}$," Chemical Engineering Journal, vol. 241, pp. 92-102, 2014.

[9] T. Zhu, L. Lu, Y. Dai et al., "Preparation for nano-titania catalyst and its application for benzene decomposition," Nature Environment and Pollution Technology, vol. 12, no. 4, pp. 675678, 2013.

[10] K. Zhang, X. F. Du, M. B. Katz et al., "Creating high quality $\mathrm{Ca}: \mathrm{TiO}_{2}-\mathrm{B}\left(\mathrm{CaTi}_{5} \mathrm{O}_{11}\right)$ and $\mathrm{TiO}_{2}-\mathrm{B}$ epitaxial thin films by pulsed laser deposition," Chemical Communications, vol. 51, no. 41, pp. 8584-8587, 2015.

[11] A. A. Assadi, J. Palau, A. Bouzaza, J. Penya-Roja, V. MartinezSoriac, and D. Wolbert, "Abatement of 3-methylbutanal and trimethylamine with combined plasma and photocatalysis in a continuous planar reactor," Journal of Photochemistry and Photobiology A: Chemistry, vol. 282, pp. 1-8, 2014.

[12] J. Palau, A. A. Assadi, J. M. Penya-Roja, A. Bouzaza, D. Wolbert, and V. Martínez-Soria, "Isovaleraldehyde degradation using UV photocatalytic and dielectric barrier discharge reactors, and their combinations," Journal of Photochemistry and Photobiology A: Chemistry, vol. 299, pp. 110-117, 2015. 
[13] D. Lopatik, D. Marinov, O. Guaitella, A. Rousseau, and J. Röpcke, "On the reactivity of plasma-treated photo-catalytic $\mathrm{TiO}_{2}$ surfaces for oxidation of $\mathrm{C}_{2} \mathrm{H}_{2}$ and CO," Journal of Physics D: Applied Physics, vol. 46, no. 25, pp. 203-208, 2013.

[14] B. Dou, F. Bin, C. Wang, Q. Jia, and J. Li, "Discharge characteristics and abatement of volatile organic compounds using plasma reactor packed with ceramic Raschig rings," Journal of Electrostatics, vol. 71, no. 5, pp. 939-944, 2013.

[15] A. A. Assadi, A. Bouzaza, C. Vallet, and D. Wolbert, "Use of DBD plasma, photocatalysis, and combined DBD plasma/ photocatalysis in a continuous annular reactor for isovaleraldehyde elimination-synergetic effect and byproducts identification," Chemical Engineering Journal, vol. 254, pp. 124-132, 2014. 



Submit your manuscripts at http://www.hindawi.com
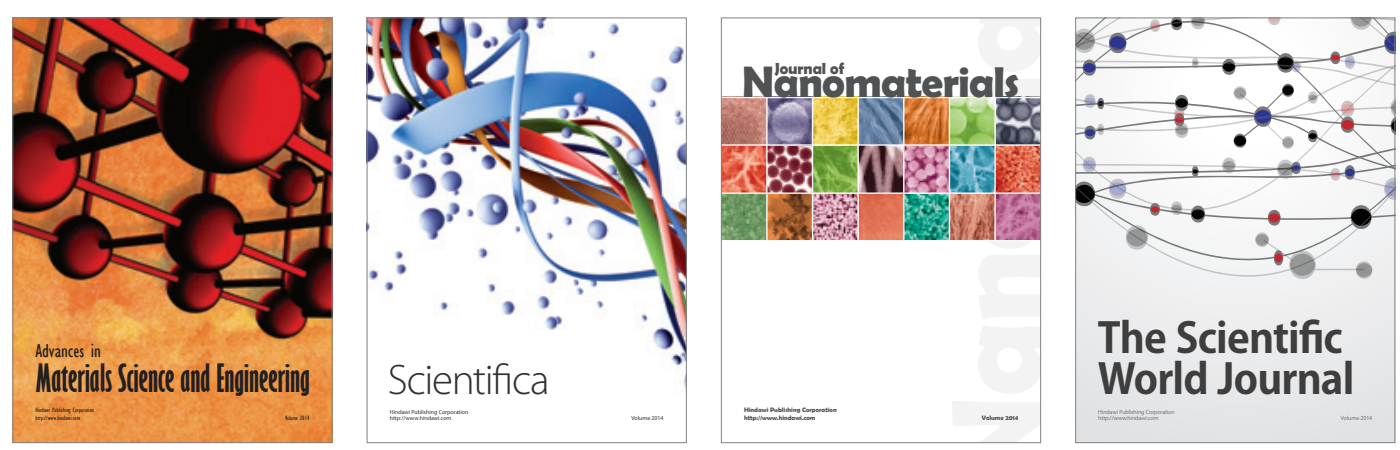

\section{The Scientific World Journal}
